
\title{
25 Research Soure \\ Low sense of coherence in long-term follow up of adolescents with anorexia nervosa
}

\section{Jan Vagedes}

Die Filderklinik gGmbH

Theresa Kleih

Charite Universitatsmedizin Berlin

\section{Cara Simmance}

Die Filderklinik gGmbH

Jenifer Svaldi

Eberhard Karls Universitat Tubingen

\section{Martin Hautzinger}

Eberhard Karls Universitat Tubingen

Tido von Schoen-Angerer ( $\nabla$ tido.von.schoenangerer@gmail.com )

Filderklinik https://orcid.org/0000-0003-3601-7480

\section{Research article}

Keywords: anorexia nervosa, bulimia, sense of coherence, mental health

Posted Date: November 7th, 2019

DOl: https://doi.org/10.21203/rs.2.16948/v1

License: (c) (i) This work is licensed under a Creative Commons Attribution 4.0 International License. Read Full License

Version of Record: A version of this preprint was published at Nordic Journal of Psychiatry on February 9th, 2021. See the published version at https://doi.org/10.1080/08039488.2021.1877814. 


\section{Abstract}

Background: Sense of coherence is a personal resource known to be low in eating disorders. We wanted to know if sense of coherence is still correlated to anorexia symptoms several years after initial hospitalisation for anorexia.

Methods: 86 former female patients diagnosed with anorexia were contacted 5-11 years after hospitalisation in a German hospital; 68 of 149 women (46\%) could be contacted and agreed to participate in a survey with the Eating Disorder Inventory (EDI-2) and the Sense of Coherence Questionnaire (SOC-13).

Results: $17.6 \%$ of participants stated that they suffered from an eating disorder currently, with $7.4 \%$ having anorexia nervosa. Mean EDI-2 subscales (except for the bulimia sub-scale) were in the <40th percentile for women with anorexia. Sense of coherence was low (percentile rank 20). All EDI-2 subscales correlated negatively with the SOC-13 score $(p<0.01)$.

Conclusions: The sense of coherence is low in long-term follow up of anorexia nervosa and is correlated with on-going anorexia symptoms.

\section{Introduction}

The sense of coherence is considered a personal resource that explains why some humans stay well and may even improve their overall wellbeing in situations of stress and hardship.[1] Antonovsky introduced the concept of sense of coherence (SOC) and defined it through three elements: comprehensibility (confidence that external and internal stimuli are explicable), manageability (ability to meet the demands posed by these stimuli) and meaningfulness (confidence that the demands pose a challenge worthy to engage with). [2]. Antonovsky's work represented a paradigm shift from the dominant pathogenic focus to a salutogenic focus where personal resources and health determinants are valued. The $\mathrm{SOC}$ scale that Antonovsky developed has been found to be strongly related to health, especially mental health, regardless of age, sex, ethnicity and nationality.[1] Conversely, SOC was negatively associated with mental health issues such as anxiety, burnout, depression, and post-traumatic stress disorder. Further, it was shown that SOC and mental health are independent but correlated constructs whereby SOC seems to be a mediator between stress and mental health.[1] SOC is a relatively stable trait, reaching stability between 16-19 years, with slight improvement with age.[3]

Few studies have examined the association of SOC with eating disorders. Among patients with different eating disorders, low SOC was associated with high perfectionism, a key eating-disorder symptom.[4] SOC was low in adults with Bulimia nervosa (BN) patients and had a negative correlation with depression and physical complaints, but a positive correlation with quality of life.[5] SOC was low even in disordered eating pathology, a term referring to a moderate level of disturbed eating patterns.[6] 
Given paucity of data of SOC in AN, limited understanding of the long-term consequences of AN and lack of data of SOC in long-term follow up of AN, we aimed to study if SOC is low and if it is associated with on-going eating-disorder symptoms in the long-term follow-up of AN.

\section{Methods}

\section{Participants and data collection}

The study was carried out among patients who had been diagnosed with AN during adolescence, treated between January 1, 2003 and December 31, 2008 in an eating disorder inpatient unit at the Filderklinik (Filderstadt, Germany). The unit combines individual psychotherapy, systemic family therapy and anthroposophic medicine (a complementary medicine system).[7] Anthroposophic medicine aspects included external applications (metabolism stimulating packs, rhythmic therapeutic massages) as well as art and movement therapy.

The former patients were included when female and diagnosed with a DSM-IV diagnosis of AN (not prepubertal) at the time of an inpatient treatment that lasted for at least 28 days. Attempts were made to contact all former patients, or as appropriate their legal guardians, by phone between August 2013 and May 2014, i.e. 5-11 years after their hospitalization (mean 7.24 years, SD 1.56). Further material was sent by post and the participants were asked to sign an informed consent form. The study was approved by the ethics committee of Tübingen University, approval number 430/213B01.

\section{$\underline{\text { Instruments }}$}

Eating Disorders Inventory (EDI-2): Eating disorders specific symptoms were assessed by using the German version of the EDI-2.[8] Normal values for a German population were taken from Paul \& Thiel. Validity and reliability of the EDI-2 subscales have been verified.[8]

\section{The Sense of Coherence Scale}

The Sense of Coherence Questionnaire developed by Antonovsky, short version (SOC-13) was used in its German translation.[9] The SOC-13 has been validated in numerous studies; validation in a normal German population established consistency with a Cronbach alpha value of 0.85 and a median score of 65.17 (SD 11.6); the median score for German women age 18 to 40 years was 64.[10]

\section{Data Analysis}

The statistical analysis was performed using the Statistical Package for Social Sciences (IBM SPSS Statistics, version 22). For correlation tests, the Pearson correlation was used. In case of incomplete data entry, the score was to be replaced with the mean of the variable. As done by Petersson et al,[4] we also performed a median split to make these two studies comparable. The data was divided into two groups by median-split of the SOC scores ("Iow SOC" and "very low SOC"). We used Man-Whitney-U-Test 
comparing SOC mediansplit groups with respect to the EDI-2 subscales. A p-value $<.005$ was considered as statistically significant.

\section{Results}

149 female patients had been hospitalized during the inclusion period of which 83 could be contacted. The remaining 66 could either not be reached for lack matching address (42), gave no response (13), could not be reached because relatives prevented the contact (7) or had died (4). Of the 83 women, 68 agreed to participate in the study ( $46 \%$ of overall sample).

At the time of their initial hospitalization, the mean age of these women was 15.61 years (SD 1.76), mean disease duration prior to hospitalization was 13.43 months (SD 10.51), mean BMI was $14.66 \mathrm{~kg} / \mathrm{m}^{2}$ (SD 1.69). At hospital discharge mean BMI was $16.89 \mathrm{~kg} / \mathrm{m}^{2}$ (SD 1.53), mean duration of hospitalization was 68 days (SD 19.17).

At the time of contact for this study, mean age was 23.04 years (range 18-27, SD 2.19), mean BMI was $19.99 \mathrm{~kg} / \mathrm{m}^{2}$ (range 15.8-24.5, SD 2.05). 25 (36.7\%) women had been re-hospitalized during the follow-up interval. 12 (17.6\%) participants stated that they currently had an eating disorder diagnosis, with 5 (7.3\%) having anorexia nervosa, 4 (5.9\%) bulimia nervosa, and 2 (2.9\%) a binge eating disorder.

For the eating disorders specific symptoms, we found EDI-2 subscales $\leq 35^{\text {th }}$ percentile range (with the exception for bulimia subscale) when using reference values for women with anorexia of restrictive type, and in the $50-90^{\text {th }}$ percentile when using reference values for normal women (see table 1). Mean value of the SOC-13 scale was 53.59, SD=7.93, percentile rank 20, indicating a low sense of coherence. Each of the EDI-2 subscales correlated negatively with the SOC total score (table 1).

We carried out a median split by dividing the SOC results into two groups: "very low SOC" for SOC $\leq 53$ vs. "low SOC" for SOC > 53. The "very low" SOC group had significantly higher scores on all EDI-2 subscales (table 2), providing another way to demonstrate the EDI-2 subscale and SOC correlation.

Furthermore, all women with an eating disorder at time of this analysis were found in the in "very low" SOC median split group. Of the 25 women with subsequent hospitalisations, 19 were in "very low" SOC, 6 in "low" SOC group.

\section{Discussion And Conclusions}

Our study shows that SOC is very low during a long-term follow-up of women with AN. Sense of coherence was negatively correlated with EDI-2 subscales in this cohort of women with previous anorexia nervosa hospitalisation: this correlation was previously shown for eating disorders in general but is here 
shown for the first time specifically in anorexia nervosa patients. The correlation of SOC and anorexia symptoms is high even 5-11 years after initial hospitalisation.

Baseline characteristics and outcomes of this cohort appeared broadly representative and comparable to other European programs. $[8,11]$ A limitation of our study is that the SOC and EDI-2 subscales at time of hospitalisation were not known and we cannot determine how SOC changed over time. As SOC is considered to stabilise at age 16-19 years a low SOC was expected for this cohort.[3] Tagay showed SOC improvement during anorexia inpatient treatment but effect levels were low and mean SOC remained below normal, while effect levels for symptom improvement were high.[12] The same study also showed that a higher sense of coherence at hospital admission was a predictor for reduced anorexia symptoms at discharge.

Future studies should assess $\mathrm{SOC}$ at baseline and different time points of AN follow up and test if baseline SOC is a long-term predictor of anorexia symptoms outcomes. A better understanding of the possibility to reinforce the sense of coherence as a prevention or treatment measure for patients with disordered eating pathology and eating disorders would be a particularly important subject for future research.

\section{Declarations}

Ethical approval and consent to participate: The study was approved by the ethics committee of Tübingen University, approval number 430/213B01. All procedures performed in studies involving human participants were in accordance with the ethical standards of the institutional ethics committee of Tübingen University and with the 1964 Helsinki declaration and its later amendments or comparable ethical standards. Participants were contacted by phone; further material was sent by post and the participants were asked to sign an informed consent form.

Consent for publication: not applicable.

Availability of data and materials: The datasets used and/or analysed during the current study are available from the corresponding author on reasonable request.

Competing interests: the authors declare that they have no competing interests.

Funding: The ARCIM Institute is supported by an unrestricted grant by the Mahle Foundation. The funder had no role at any stage in the analysis or in manuscript preparation.

Author's contributions: JV conceptualized and supervised the study, led the data analysis and interpretation and revised the manuscript. TK wrote the study protocol, interviewed participants and analyzed the data. CS analyzed and interpreted the data and wrote part of the manuscript. JS critically reviewed the manuscript. MH supervised the study. TvSA interpreted the data and wrote the manuscript. All authors read and approved the final manuscript. 
Acknowledgements: We thank Dr Karl-Heinz Ruckgaber, Jürgen Weik and Dr Eduard Helmert for their support and input during data collection and analysis.

\section{References}

1. Eriksson M, Lindström B: Antonovsky's sense of coherence scale and the relation with health: a systematic review. J Epidemiol Community Health 2006, 60(5):376-381.

2. Antonovsky A: The structure and properties of the sense of coherence scale. Soc Sci Med 1993, 36(6):725-733.

3. Kröninger-Jungaberle $H$, Grevenstein $D$ : Development of salutogenetic factors in mental health Antonovsky's sense of coherence and Bandura's self-efficacy related to Derogatis' symptom check list (SCL-90-R). Health and Quality of Life Outcomes 2013, 11(1):1-9.

4. Petersson S, Perseius K-I, Johnsson P: Perfectionism and sense of coherence among patients with eating disorders. Nordic journal of psychiatry 2014, 68(6):409-415.

5. Tagay S, Mewes R, Brähler E, Senf W: Sense of coherence in female patients with Bulimia Nervosa: A protective factor of mental health? [Sense of coherence bei Bulimie-Patientinnen: Ein protektiver faktor für psychische gesundheit?]. Psychiatrische Praxis 2009, 36(1):30-34.

6. Latzer Y, Weinberger-Litman SL, Spivak-Lavi Z, Tzischinsky O: Disordered Eating Pathology and Body Image Among Adolescent Girls in Israel: The Role of Sense of Coherence. Community Ment Health J 2019.

7. Kienle GS, Albonico H-U, Baars E, Hamre HJ, Zimmermann P, Kiene H: Anthroposophic Medicine: an integrative medical system originating in Europe. Global Advances in Health and Medicine 2013, 2(6):20-31.

8. Paul T, Thiel A: Eating Disorder Inventory. Deutsche Version.: Hogrefe; 2004.

9. Abel T, Kohlmann T, Noack R: Eine deutsche Übersetzung des SOC-13. In. Universität Bern: Abteilung für Gesundheitsforschung des Instituts für Sozial-und Präventivmedizin; 1995.

10. Schumacher J, Wilz G, Gunzelmann T, Brahler E: [The Antonovsky Sense of Coherence Scale. Test statistical evaluation of a representative population sample and construction of a brief scale]. Psychother Psychosom Med Psychol 2000, 50(12):472-482.

11. Steinhausen H-C, Grigoroiu-Serbanescu M, Boyadjieva S, Neumarker K, Winkler Metzke C: Course and predictors of rehospitalization in adolescent anorexia nervosa in a multisite study. Int J Eat Disord 2008, 41(1):29.

12. Tagay S, Düllmann S, Schlegl S, Nater-Mewes R, Repic N, Hampke C, Brähler E, Gerlach G, Senf W: [Effects of inpatient treatment on eating disorder symptoms, health-related quality of life and personal resources in anorexia and bulimia nervosa]. PPmP: Psychotherapie Psychosomatik Medizinische Psychologie 2011, 61(7):319-327. 


\section{Tables}

Table 1. Eating Disorder Inventory-2 (EDI-2) subscales and correlation matrix of Sense of Coherence (SOC). $\mathrm{N}=68 .{ }^{*} p<0.05, * * p<0.01,{ }^{* * *} p<0.001$

\begin{tabular}{lll}
\hline EDI-2 subscales & $\begin{array}{l}\text { Mean (SD) percentile anorexia/normal } \\
\text { women }\end{array}$ & $\begin{array}{l}\text { SOC-13 } \\
\text { correlation }\end{array}$ \\
\hline Drive for thinness & $21,22(10.79) 30 / 70$ & $-0.63^{* * *}$ \\
Bulimia & $14,96(9.51) 68 / 90$ & $-0.52^{* * *}$ \\
Body dissatisfaction & $31,37(13.66) 30 / 58$ & $-0.70^{* * *}$ \\
Ineffectiveness & $26,56(10.77) 19 / 77$ & $-0.85^{* * *}$ \\
Perfectionism & $18,69(6.02) 35 / 68$ & $-0.36^{* *}$ \\
Interpersonal distrust & $18,21(6.91) 20 / 50$ & $-0.77^{* * *}$ \\
Interoceptive & $27,21(10.95) 25 / 83$ & $-0.77^{* * *}$ \\
awareness & $22,49(7.09) 23 / 63$ & $-0.64^{* * *}$ \\
Maturity fears & $18,84(7.42) 25 / 74$ & $-0.70^{* * *}$ \\
Asceticism & $24,46(9.11) 33 / 66$ & $-0.77^{* * *}$ \\
Impulse regulation & $22,38(8.20) 20 / 57$ & $-0.81^{* * *}$ \\
Social insecurity & 22,45
\end{tabular}

Table 2: Sense of Coherence Median Split 


\begin{tabular}{|c|c|c|c|c|c|}
\hline & & & & & Value \\
\hline rive for thinness & $26.7(9.8)$ & ( 23.3 & $15.5(8.8)$ & ( 12.3 ; & $<.001$ \\
\hline iulimia & $19.1(11.1)$ & ( 15.3 & $10.6(5.0)$ & $12.4)$ & $<.001$ \\
\hline $\begin{array}{l}\text { iody } \\
\text { issatisfaction }\end{array}$ & $38.4(12.2)$ & ( 34.1 ; & $23.8(11.3)$ & ( 19.7 ; & $<.001$ \\
\hline heffectiveness & $33.6(9.3)$ & ( 30.4 ; & $18.7(5.5)$ & ( 16.7 ; & $<.001$ \\
\hline 'erfectionism & $20.6(6.2)$ & $(18.4 ; 22.7)$ & $16.8(5.0)$ & $(15.0$ & $<.001$ \\
\hline $\begin{array}{l}\text { aterpersonal } \\
\text { istrust }\end{array}$ & $22.1(6.9)$ & $(19.7 ; 24.5)$ & $13.9(4.0)$ & $(12.4 ; 15.3)$ & $<.001$ \\
\hline $\begin{array}{l}\text { tteroceptive } \\
\text { wareness }\end{array}$ & $34.2(10.0)$ & $(30.8 ; 37.7)$ & $19.6(6.2)$ & $(17.3 ; 21.8)$ & $<.001$ \\
\hline Taturity fears & $26.0(7.0)$ & $(23.5 ; 28.5)$ & $18.7(5.2)$ & ( 16.8 ; & $<.001$ \\
\hline sceticism & $22.8(6.4)$ & ( 20.5 ; & $14.3(5.2)$ & $(12.4$ & $<.001$ \\
\hline npulse regulation & $30.1(8.0)$ & ( 27.4 & $17.8(4.1)$ & ( 16.3 & $<.001$ \\
\hline ocial insecurity & $27.1(6.6)$ & $(24.8$ & $16.6(5.0)$ & ( 14.8 ; & $<.001$ \\
\hline
\end{tabular}

